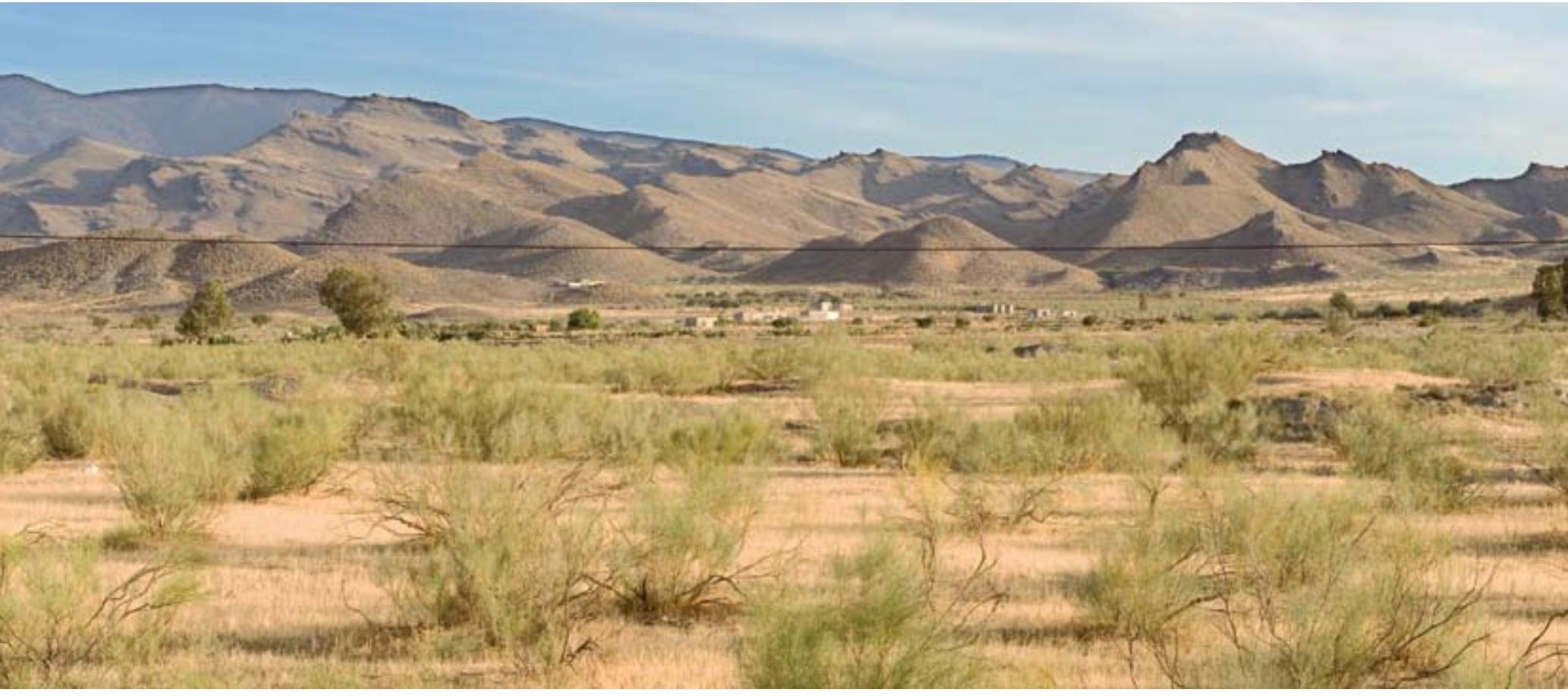

Vista del desierto de Tabernas desde la carretera que va desde Tabernas a Castro de Filabres y Velefique. Foto: Juan Carlos Cazalla, IAPH

En el valle del Andarax y en el de Tabernas podemos apreciar esta oposición secano-regadío, tan característica del paisaje mediterráneo, de fuertes contrastes entre una zona semiárida y árida, con unas montañas muy erosionadas y desertificadas y el contrapunto del verde de las zonas agrícolas de las vegas 


\section{Paisaje vivo, en permanente evolución}

Juan Salvador López Galán,

Departamento de Protección del

Patrimonio Histórico, Delegación

Provincial de Cultura de Almería

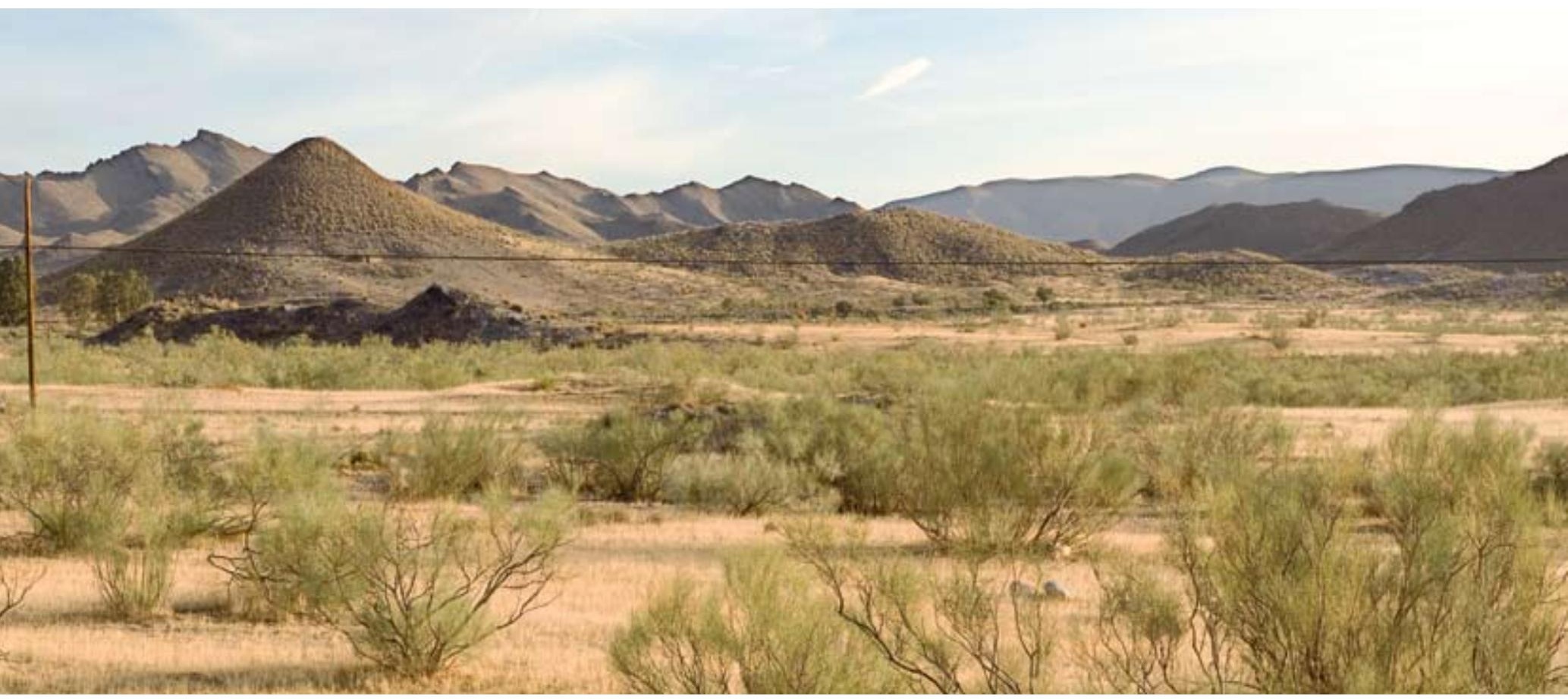

Almería es una tierra de contrastes que presenta paisajes muy diferentes desde el interior hasta la costa, entre las zonas montañosas de sierra de Gádor en La Alpujarra, la sierra de los Filabres y Sierra Maria y los valles que conforman los rios Andarax y Almanzora, con las singulares zonas desérticas de Tabernas, los Karts de yesos de Sorbas, y las calderas volcánicas de Rodalquilar (Nijar) y las dunas fósiles del Parque Natural de Cabo de Gata (Nijar).

En el valle del Andarax y en el de Tabernas podemos apreciar esta oposición secano-regadío, tan característica del paisaje mediterráneo, de fuertes contrastes entre una zona semiárida y árida, con unas montañas muy erosionadas y desertificadas y el contrapunto del verde de las zonas agrícolas de las vegas que forman el río Andarax y las diferentes ramblas que lo constituyen. Es un paisaje vivo, que sigue en permanente evolución, y que desde el cultivo del olivar y los frutales, con predominio de la morera en el siglo XVI, se pasó a la radical desforestación que conllevaba la minifundista minería del plomo del siglo XIX, y a la construcción de pequeñas terrazas de cultivo en laderas de fuertes pendientes y a la ampliación de la infraestructura de regadios, para el cultivo de los parrales de la uva de mesa desde mediados del siglo XIX y principios del XX. Posteriormente, dichos parrales fueron sustituidos por los cítricos actuales, con predominio del naranjo y los mandarinos.

Pero quizás este sea un nuevo momento de transición, de cambio e incertidumbre, donde el cultivo de los cítricos orientado a la comercialización, primero internacional y luego nacional, ha dejado de ser rentable por varias causas, entre las que destaca la pérdida de subvenciones comunitarias y el alto coste de producción y donde las pequeñas explotaciones son dirigidas por una generación a punto de jubilarse.

En esta sección de "Bienes, Paisajes e Itinerarios" abordaremos a continuación los diferentes periodos de ocupación del territorio, desde Los Millares a la arquitectura defensiva medieval, la industria del cine de mediados del siglo XX generada en los escenarios naturales del desierto de Tabernas, el patrimonio urbano de Ciudad Jardín de Almería, el Museo de Almería y el aprovechamiento histórico de las fuentes termales en los balnearios de Alhama y Sierra Alhamilla (Pechina). 